\title{
EL CULTO AL SANTO DAIME EN LA ESCRITURA DE NÉSTOR PERLONGHER: ENTRE LA INTEGRACIÓN DEL IMAGINARIO DAIMÍSTICO COMO SUSTRATO TEXTUAL Y LA CREACIÓN DE HIMNOS DE FINALIDAD RITUAL ${ }^{1}$
}

\author{
POR \\ Jorge Ignacio Cid Alarcón \\ Universidad Adolfo Ibáñez
}

En este artículo analizaremos la trascendencia poética que tuvo la participación de Néstor Perlongher en la espiritualidad amazónica del Santo Daime. Con este fin analizaremos dos obras que se relacionan directamente con la experiencia de consumo de la ayahuasca en un contexto ritual, el libro de poemas Aguas Aéreas, en el que reconocemos la integración de elementos relativos al trance místico, y el texto "Autosacramental del Santo Daime", cuya utilidad votiva evaluaremos a continuación.

En este contexto, lo sagrado se expresa como el contacto con un lenguaje visual y textual cerrado a la decodificación, al que el poeta accede por medio de estados modificados de conciencia, causados por el consumo de la liana sagrada, la ayahuasca. El carácter sagrado de esta práctica con efecto de trance radica en su contexto de realización religioso, al que Perlongher se suma como un feligrés convencido (según confirman pasajes de su correspondencia que revisaremos más adelante) en el que el sacerdote (maestro) cumple con inducir y guiar el trance (miraçoes) a través de la entonación de himnos y la percusión.

Con el fin de analizar la forma en que se manifiesta textualmente la influencia de esta experiencia en la obra de Perlongher, describiremos en primer lugar algunos rasgos de su lenguaje poético para luego demostrar, a través de la revisión de entrevistas, cartas y textos literarios, de qué manera trasciende la experiencia del Daime en su escritura.

Sobre la poesía de Néstor Perlongher: INTERlengua y heteroglosia como eStrategias DE DESESTABILIZACIÓN GRAMATICAL

La obra poética de Néstor Perlongher desarrolla una reflexión sobre lenguas de baja estandarización, incurriendo en su fijación poética; y sobre las operaciones de

\footnotetext{
1 Este artículo forma parte del proyecto FONDECYT Postdoctoal n ${ }^{\circ}$ 3160054: "Poéticas de la
} incertidumbre neobarroca: un estudio comparado de tres escritores chilenos y tres latinoamericanos". 
generatividad y transformación lingüística que le son fuente de desarrollo. En este sentido, el poeta neobarroso no sólo se siente atraído por el portuñol y el lunfardo, sino que además por lo que éstos representan de manera más profunda: un acervo de palabras en constante movilización y riesgo de desaparición.

La explotación poética de elementos lingüísticos rescatados de estos idiomas evanescentes funciona como la posibilidad de anulación poética de matrices de subjetividad que determinan que toda expresión sea mediatizada por los moldes simbólicos que la lengua ha predeterminado. Ante esta conciencia, el poeta opone, en un gesto similar al descrito por Adrián Cangi, ${ }^{2}$ la fuerza idiomática de la migración como un placebo de diversidad no absorbida, un léxico plural e insólito que se resiste a que los rasgos en los que se funda su particularidad sean abstraídos por la gramática dominante. Esto tiene como resultado la concepción de la escritura como un ejercicio libertario y profusamente desagradable a los ojos de la crítica aquiescente de la gramática normativa y de las literaturas estandarizadas.

$\mathrm{La}$ atracción por este tipo de lenguas se evidencia también en su acercamiento a la espiritualidad del Santo Daime y en la forma en que éste se refleja en su escritura. Esta religión se caracterizaba por un rito en el que tenía lugar el consumo ritual de una bebida psicoactiva, preparada con lianas de ayahuasca y, además, por el canto de himnos cuyos ritmos estimulaban el trance extático (MacRae, Guiado por la luna 36). Son precisamente en estos himnos rituales en los que se cristaliza una interesante gama de rasgos propios a la lengua de sus feligreses, eminentemente mestiza, y en tensión con la lengua portuguesa estándar.

Es de este modo como, al observar las transcripciones de himnos daimísticos que han llegado a nosotros, ${ }^{3}$ podemos advertir que sus rasgos preeminentes como figuras y metáforas relativas a una divinización del mundo vegetal conviven con un lenguaje matizado con rasgos de la oralidad, advirtiéndose cuestiones ligadas al tema de la interlengua en el caso de la utilización de un portugués denominado caboclo. Estos himnos son cantados por una feligresía que, en su mayoría no ha tenido acceso a una educación formal, lo que se evidencia en un portugués hablado que, desde la perspectiva letrada, resulta rústico, particularmente, por su desapego a las normas gramaticales y por las interferencias de lenguas vernáculas. ${ }^{4}$

2 "Las lenguas nacionales a través de la pedagogía y el uso jurídico matrizan la subjetividad para liberarla de las particularidades históricas, sus costumbres locales, sus concepciones ancestrales, sus prejuicios y su lengua materna, es decir de su campo afectivo. La gramática es el sueño de una igualdad y un pacto de libertad que el Estado estructura como desigualdad real en la organización al acceso pedagógico. Las fuerzas migrantes, la diversidad no absorbida funciona como deriva amenazante que deja errar sus flujos sobre el cuerpo lleno de lenguaje" (Cangi 266).

3 Algunos de estos himnos pueden encontrarse en el sitio web de la iglesia del Santo Daime.

4 El antropólogo Edward McRae en conversación con Perlongher se refiere a este aspecto de la siguiente manera: "Sobre la diferencia cultural del Daime: es muy popular esta cosa cabocla, amazónica, y una de

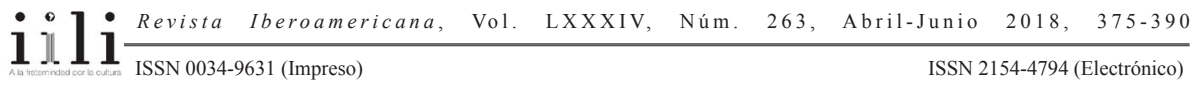


El contacto con los himnos del Santo Daime constituye el encuentro del poeta con un sustrato textual caracterizado por su naturaleza estructuralmente errática y que, así como el lunfardo y el portuñol, logra erigirse como un blasón que marca origen e historia de una tribu. Ahora bien, el portugués caboclo constituiría una historia ya no de exilio como en el caso del portuñol, sino más bien de mestizaje, en la medida en que esta voz de origen tupi-guaraní refiere el color cobrizo, tradicionalmente asociado a mestizos descendientes de blancos e indígenas de la región del estado brasileño de Acre. Al mismo tiempo, esta variante connotaría un rasgo estigmatizante, en la medida en que la manifestación cabocla de dicha lengua es entendida como realización empobrecida, simplificada, como sucesión de faltas al código de la lengua.

La apelación de lengua cabocla opone no sólo la idea de una -en atención a las dinámicas identitarias- lengua de mestizos a la lengua de blancos, sino también la noción de lengua urbana a la de su variante del interior. Lo anterior indicaría que la versión de la lengua portuguesa en que se sustenta el ejercicio hímnico del Daime sería en sí mismo un gesto de alteridad reforzado por su condición de religiosidad selvática.

Las interferencias del portugués en su poesía asociados al portuñol corresponden a elementos rescatados del habla de las bocas, ${ }^{5}$ sectores populares de la ciudad en que convergían individuos trashumantes vinculados a formas de vida delictual. Se trataba, por lo tanto, de un fenómeno lingüístico urbano, particularmente vinculado a las grandes metrópolis en donde converge mayoritariamente la inmigración, mientras que, en el caso de la vertiente cabocla del portugués, su manifestación desapegada de la gramática, guarda relación con su condición de lengua del interior, selvática $\mathrm{y}$, a menudo, de segunda lengua teniendo como primera una de tipo indígena.

Entre ambas variantes del portugués (el portuñol, que Perlongher conoció bien en las Bocas de São Paulo y, el caboclo, que caracterizaba el habla y los himnos de los feligreses del Santo Daime) se constatan diferencias tales como el lugar en donde éstas se manifiestan, así como también el soporte por medio del cual accede el poeta a ellas. En el primer caso es la oralidad, mientras que en el segundo, el poeta tiene contacto con ella a través de una forma poética ritualizada constituida por los himnos

las primeras cosas que se perciben son los millares de errores de concordancia, y cosas así, que tienen los himnos. Ahora, para mí no son errores, son formas diversas de usar la lengua, otros patrones, etc. [...] Hoy en día, para mí, como para otras personas culturalmente sofisticadas que están en el Daime, este lenguaje, más 'pobre', más 'simple', es importante por su capacidad expresiva de la pertenencia a un grupo de referencia más amplio. Es como decir 'Yo soy del Daime'. Esos signos pertenecen al cuerpo de himnos del Daime, donde la lengua portuguesa es un poco diferente y además se están siguiendo otros patrones estéticos" ("Recibir" 386).

5 Como, por ejemplo, Boca do Lixo sector de la ciudad de São Paulo en el que se concentraba el comercio sexual y donde Perlongher se instaló el año 1981 con el fin de desarrollar su investigación de maestría sobre la prostitución masculina en entornos urbanos a través de una metodología de observación participante.

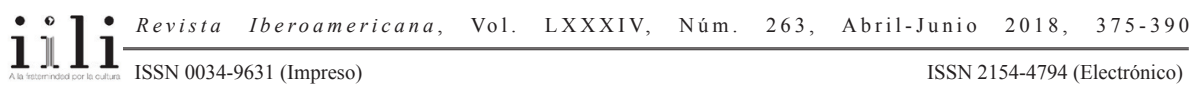


del Daime. Si bien estas consideraciones respecto del portuñol y el portugués caboclo buscan caracterizar hasta qué punto el poeta neobarroso se sentía atraído por las variantes lingüísticas no estandarizadas, no obviamos el hecho de que su adhesión a dicha espiritualidad, y con ella a sus lenguajes característicos, esté relacionada con un asunto de índole más bien ideológico. En este sentido, resulta interesante destacar que el poeta reconoce en el rito del Santo Daime una inversión total de las coordenadas de dominación, en la medida en que éste utiliza la versión cabocla de la lengua situándola como soporte lingüístico de sus himnos y bloqueando así las matrices de subjetividad transportadas por el portugués estándar.

\section{ESCRIBIR BAJO LOS EFECTOS DEL DAIME VERSUS ESCRIBIR INSPIRADO POR LA EXPERIENCIA DEL DAIME}

En una de las entrevistas realizadas por Edward MacRae, el poeta ${ }^{6}$ da cuenta de la trascendencia política que éste reconoce en el portugués que caracteriza al Daime y como éste se vincula consonantemente con el gesto contrasistémico del lunfardo y portuñol. Ahora bien, si estos últimos eran entendidos como oposición a la lengua estándar dentro de su mismo carácter urbano, el caboclo viene a cuestionar la lengua oficial desde el punto de vista de su real cobertura en el territorio nacional y, por extensión, la eficacia de su hegemonía.

Resulta importante preguntarnos por las razones de fondo que llevaron a Perlongher a darle una trascendencia literaria a su práctica del Santo Daime. En este sentido, a las ya indicadas consonancias discursivas entre el portugués caboclo y las anteriormente detectadas en su poética, se suma el hecho de que el Daime fue entendido por él como un soporte poético / religioso acorde a los valores de trasgresión generativa que caracterizaron su poesía. En su artículo "La religión de la ayahuasca" explica la relación que incluye entre espiritualidad y lengua con el fin de definir al Daime, ${ }^{7}$ de la que se

6 Lo anterior puede verse en las siguientes declaraciones del poeta: "Otra cosa interesante es que se transforma el portugués, como portugués caboclo, en el himno oficial. Eso es genial. Porque el Daime tiene una relación de inversión en relación a Occidente. Por lógica, el Acre debe depender de Rio de Janeiro y de Sao Paulo, con su capitalismo y todo eso: en el Daime eso está invertido, es el Acre el que gobierna. [...] Son muy graciosos los americanos tratando de cantar en portugués $-y$ en portugués caboclo, además-, o los alemanes, porque es una inversión total de las coordenadas de dominación" ("Recibir" 387).

7 "El hecho de que no haya una doctrina escrita, sino que ella se derive de los contenidos de los himnos recibidos por los acólitos favorece dicha plasticidad proliferante [...] en un indiscernible patois (o paté) espiritual. [...] Hasta libros sobre el tema como el de Gregorim (ya citado), se integran en esa melaza espiritual de límites y formas difusas. Pero esto no sería necesariamente un defecto de religión, sino que podría incluso ser una virtud, esta abundancia y experimentación (casi gimnástica, empero...) de códigos religiosos diversos y superpuestos entre sí, en una yuxtaposición indefinible próxima al supermercado de cultos afrocubanos que Fichte descubre en Miami” (161, énfasis mío). 
desprende que la influencia del Santo Daime en su obra tiene que ver con la asimilación de dicha espiritualidad a una manifestación lingüística entendida como una nueva textura idiomática que se integra a las operaciones transtextuales características de su escritura, tal como puede constatarse en su referencia a ella como patois espiritual. De esta forma, otorga a la religión amazónica la categoría de variante lingüística alterna a la lengua estándar en lo que describe como "una suerte de licuefacción de los códigos religiosos" (Prosa 161).

Este aspecto puede refrendarse en la percepción que el poeta tenía de las comunidades religiosas en donde se practicaba el Daime como sitios en los que la vida espiritual no se circunscribía exclusivamente a los santuarios, trascendiendo hacia los intercambios cotidianos que, según describe el poeta, estaban marcados por la poesía y una permanente reflexión filosófica tal como se puede apreciar en una carta que Perlongher envió desde São Paulo a Sara Torres en el año 1989. ${ }^{8}$ La asimilación de la espiritualidad a un sustrato lingüístico está determinada, en gran medida, por el hecho de que el Santo Daime carecía de una doctrina escrita, rasgo que comparte con las variantes lingüísticas hasta aquí destacadas. Esto nos lleva a pensar con mayor fuerza que Perlongher se acerca al Daime no sólo por una curiosidad dogmática, sino más bien porque vio en él una nueva lengua en constante desvanecimiento capaz de reflejar el cuerpo en trance sexual, fronterizo, de enfermedad y místico que se constituye a lo largo de su poética. La idea de trance más allá de lo, en apariencia, estrictamente devocional se relaciona con los ámbitos psicológicos y sociales, tal como lo define Georges Lapassade (La transe 3), lo que explicaría la calidad de estructurante comunitario que dentro de las iglesias del Daime tenía el consumo ritual de la ayahuasca destacado por Perlongher en las crónicas sobre su experiencia en las comunidades de la Iglesia Flor das Águas.

Abordar el tema del Santo Daime en relación a Néstor Perlongher invita a reflexionar sobre la manera en que su escritura poética refiere la vida, en la medida en que constatamos una inclinación de la crítica a considerar la obra contemporánea a su participación en la espiritualidad como el producto de una inspiración religiosa pasiva. Como todo tema ligado a la poética de Perlongher, este capítulo de su obra resulta complejo y demanda desentramar ambivalencias discursivas ostensibles en la confrontación de poema, ensayo y entrevistas.

Al leer Aguas aéreas, quinto libro publicado por Perlongher, nos encontramos con un lenguaje que, desde el punto de vista de su oscuridad semántica, no difiere de los dos libros anteriores (Parque Lezama y Hule). En conjunto, estos tres poemarios

\footnotetext{
8 "Son campesinos metafísicos, todo el tiempo hablando de la luz, el cosmos, las estrellas, dios, en fin, filosofías teológicas. Y todos reciben himnos por inspiración divina, poetas muchos de ellos analfabetos, eso es impresionante. Junto a ellos, gente llegada de todas partes del mundo, un cosmopolitismo en acto, al tanto de todo. También esa integración entre campesino y exurbanos es fascinante" (Papeles 438).
}

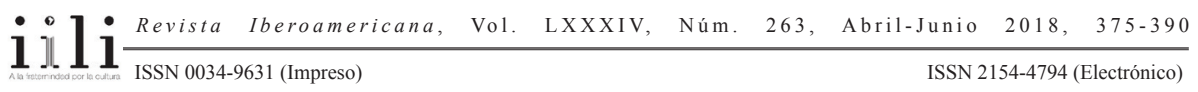


inauguran en la escritura del poeta la experimentación con el lenguaje neobarroco a través del aumento de las operaciones de artificialización neobarroca ${ }^{9}$ definidas por Sarduy. En esta etapa Perlongher deja atrás los guiños históricos con que reescribía una versión apócrifa de la historia argentina y latinoamericana, particularmente palpables en sus dos primeros libros Austria-Hungría y Alambres, para dar paso a una escritura sin concesiones con el lector que, entre sus estrategias de desestabilización semántica, consideró la inclusión de elementos heteroglósicos, provenientes del portuñol, lunfardo, francés, inglés y neologismos. En este contexto, el libro Aguas Aéreas constituye una continuación de la experimentación lingüística perlonghereana aquí descrita, al mismo tiempo que apertura un nuevo ámbito de referencia, el de los elementos ligados a la espiritualidad del Santo Daime.

Lo anterior se manifestaría a través de la asimiliación de la experiencia mística a una suerte de jerga, la que Perlongher denominó patois espiritual. La homologación de experiencia y jerga se suma a la característica en común que el poeta advertía entre la espiritualidad y la poesía moderna, a saber, una opacidad semántica que llevó al poeta, parafraseando a Lapassade, a entender la creación poética como una forma de éxtasis, según describe en el siguiente fragmento:

[...] la poesía moderna es extática porque no remite a una comprensión. No se puede encontrar un código de interpretación y hay que navegar por los flujos que la misma obra poética va indicando. A la poesía no le queda bien un saquito, un corsé que la aplaste y la traduzca a otra cosa. Este tipo de prácticas se hacen, pero son infelices y destructivas de la poesía. (Vecchio 346)

Esta cita, que nos remite a la idea de escritura mística en tanto lenguaje cerrado, muestra que Perlongher vio al Santo Daime como un lenguaje concomitante con la posibilidad de revertir las lógicas de dominación que previamente había reconocido

9 Éstas fueron definidas por Severo Sarduy con el fin de explicar los mecanismos de representación del neobarroco. A dichas operaciones corresponde la sustitución, caracterizada de la siguiente manera: "el significante que corresponde al significado $[\ldots]$ ha sido escamoteado y sustituido por otro, totalmente alejado semánticamente de él y que sólo en el contexto [...] del relato funciona, es decir, corresponde al primero en el proceso de significación" (1388); la proliferación, de la que se comenta que: "[s] u presencia es constante sobre todo en forma de enumeración disparatada, acumulación de diversos nódulos de significación, yuxtaposición de unidades heterogéneas, lista dispar y collage" (1389); y la condensación, definida por Sarduy como: "Análoga al proceso onírico de condensación es una de las prácticas del barroco: permutación, espejeo, fusión, intercambio entre los elementos -fonéticos, plásticos, etc.- de dos de los términos de una cadena significante, choque y condensación de los que surge un tercer término que resume semánticamente los dos primeros" (1392). Con la descripción de esta tercera operación, Sarduy completa lo que según su objetivo inicial puede ser considerado como un intento por introducirnos en la histología del neobarroco, la descripción de los tejidos que constituyen su lenguaje. 
en el neobarroco. Es así como que este último y la espiritualidad amazónica pueden ser entendidos como lenguajes excéntricos al estatuto lingüístico oficial.

A lo anterior se suma la preponderancia del ritmo en su escritura y la importancia sustantiva que éste manifiesta en el contexto del ritual daimístico como catalizador del éxtasis. Resulta importante precisar en este sentido que el consumo de la infusión de la ayahuasca no puede realizarse sin el acompañamiento musical consistente en himnos caracterizados por su percusión. La comunión entre bebida y música es tan relevante que la participación en el rito se conoce como recibir los himnos. ${ }^{10}$ Edward McRae describió la implicación del poeta en estas prácticas del siguiente modo:

Durante ese tiempo en que fue "daimista" Néstor "recibió" varios "himnos". Ese es un proceso análogo a la psicografía o a la inspiración divina, en que alguien recibe una música, para ser cantada bajo el efecto de la ayahuasca. Fue también en esa época que él escribió Aguas aéreas, bajo la influencia daimista, y concibió su último e inacabado proyecto de un auto religioso, al estilo barroco, sobre la ayahuasca. ("Recibir" 382)

De esta cita se desprende que el himno constituye en sí mismo el verdadero medio para el contacto con la divinidad, mientras que la bebida cumpliría el rol de facilitar el acceso a dicho éxtasis. Del mismo modo, se observa que la implicación del poeta en la espiritualidad habría tenido repercusiones al nivel escritural apuntándose, incluso, la posibilidad de la producción textual bajo el efecto del trance psicoactivo. En esta línea, el antropólogo se refiere a dos producciones de carácter literario como el producto de la participación del poeta al interior de la espiritualidad, a saber, su quinto libro de poesía y el "Autosacramental do Santo Daime”, inédito hasta el momento de su muerte y publicado por primera vez en la revista Tsé-Tsé en el 2001.

Los dichos de McRae resultan particularmente llamativos en la medida en que la cuestión del misticismo ya no es sólo como tema literario, sino como técnica de escritura. Sin embargo, creemos pertinente sopesar esta perspectiva poniendo las palabras del antropólogo bajo la sospecha de una excesiva simpatía con el Daime y el deseo de su validación artística. La influencia de esta práctica en la escritura de Aguas aéreas desde la perspectiva perlonghereana se nos revela en el postscriptum al libro: "Estos poemas se inspiran en la experiencia / del Santo Daime. Agradezco al centro Ecléctico

\footnotetext{
${ }^{10}$ Es importante indicar que, en el caso del Daime, el tambor cumple la función de guiar las visiones del viaje místico, tanto por la variación en el ritmo como en la intensidad. En relación a la importancia del tambor en los rituales de distintas culturas Eliade indicó: "le tambour joue un rôle de premier plan dans les cérémonies chamaniques. Son symbolisme est complexe, ses fonctions magiques sont multiples. Il est indispensable au déroulemente de la séance, soit qu'il porte le chaman au «Centre du Monde», soit qu'il lui permette de voler dans les airs, soit qu'il appelle et «emprisonne» les esprits, soit, enfin, que le tambourinement permette au chaman de se concentrer et de reprendre contact avec le monde spirituel qu'il ne se prépare à parcourir" (89).
}

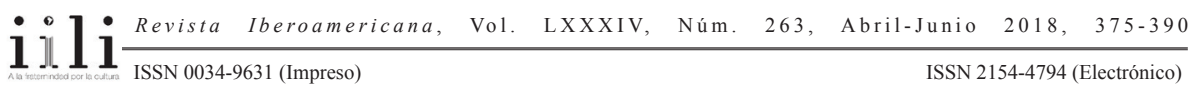


/ de Fluyente Luz Universal, 'Flor de las aguas', / de San Pablo, por el privilegio de haberme permitido / acceder a la bebida sagrada" (Poemas 301).

Destacamos la diferencia entre el hecho de escribir bajo el efecto, destacado por el antropólogo, y la idea integrada por el poeta de que dichos poemas habían sido inspirados por la experiencia. Estos matices son la puerta de entrada al cuestionamiento por la forma de trascendencia que la conmoción espiritual causada por la práctica del Daime tiene en la escritura de Perlongher. En esta línea, podríamos describir dos procesos, el primero, tiene que ver con la síntesis literaria de esta experiencia representada por su libro Aguas aéreas y, el segundo, con una síntesis de la experiencia mística con finalidad votiva como es el caso del Auto sacramental do Santo Daime.

Esta precisión resulta necesaria, pues creemos que la presencia de elementos relativos a la cosmogonía daimística en la escritura de Perlongher (luz, cosmos, estrellas, agua, entre otros) no es susceptible de ser entendida únicamente como la consignación de un trance místico, habida cuenta de la posibilidad de que éstos constituyan una explotación poética del imaginario de una religión. La integración del imaginario daimístico como sustrato textual del texto Aguas aéreas y de un himno de finalidad ritual como el Autosacramental do Santo Daime puede entenderse como la convivencia de dos voluntades dialógicas que, a pesar de su complementariedad no deben ser superpuestas.

Edward McRae le pregunta directamente al poeta si considera los textos de $s u$ quinto libro como himnos para ser utilizados en el ritual a lo que el poeta responde:

La diferencia es que el himno está al servicio de la divinidad, de la exaltación divina o sagrada o de alguna entidad [...] En el caso de Aguas aéreas, de alguna manera el tema es el Santo Daime, pero la finalidad no es religiosa, es estética. Es un goce con las palabras. Un goce inclusive de las partículas, que son. La finalidad es otra. El tema es el Daime, lo religioso, pero no tiene un mensaje diciendo 'Debemos convertirnos'. (Papeles 386)

Este comentario permite comprobar que, desde la perspectiva del poeta se descartaba el supuesto carácter devocional del libro Aguas aéreas, divergiendo de la naturaleza hagiográfica que McRae le adjudicaba. Puede parecer gratuito descartar la vocación no dogmática de estos textos conociendo la histórica aversión del poeta a ciertas corrientes confesionales, sin embargo, lo creemos pertinente debido a que el consumo de la ayahuasca en el contexto ritual cobró para el poeta una gran relevancia en el plano personal, tal como queda de manifiesto en su correspondencia con su amiga Sara Torres. Esto se evidencia tanto por la descripción que realiza de su dificultoso viaje hacia las iglesias del Daime -como Colonia Cinco mil en Rio Branco o Anajai cerca de Boca do Acre-, como por su apego a esta espiritualidad en los momentos de mayor dificultad, particularmente aquellos de mayor debilitamiento en su estado de

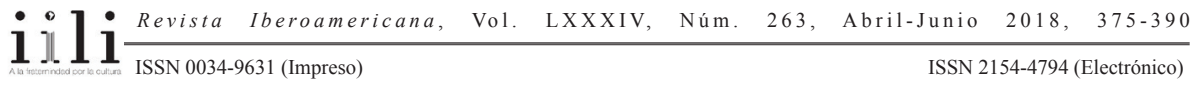


salud, según constatamos en el siguiente fragmento: "Otra de las consecuencias de toda esta situación y posiblemente muy relacionada con el bajón, es que, ahora que me veo en la proximidad de la enfermedad, me cuestiono todo lo que pensaba o escribía y me aferro a la religión del Santo Daime como única salvación; te juro que es muy difícil" (Papeles 442).

Este último aspecto aparece también en la entrevista que realizamos al escritor Roberto Echavarren en el 2010 quien expresó que el poeta: “[...] se llevó el ayahuasca [a Paris] porque creía que lo podía curar, se llevó unos frascos y bueno creo que se sintió cada vez peor y tuvo que volver a Brasil". Este tipo de consideraciones ha llevado a algunos críticos a pensar en la posibilidad de considerar a Aguas aéreas como una suerte de transcripción de su experiencia extática lo que, en atención al epílogo del libro, consideramos pertinente descartar, inclinándonos más bien por la idea de que la importancia que el Daime pudo llegar a tener como práctica personal no determina necesariamente que la totalidad de su escritura se transforme en una herramienta de devoción. Del mismo modo, consideramos que la trascendencia de la espiritualidad en la escritura de Perlongher tiene lugar, tal como se desprende de sus propias declaraciones al respecto, gracias a la homologación lingüística de la que ésta sería objeto, incorporándose a la escritura en tanto que campo semántico de índole daimístico y constituyendo una especie de mímica de su lenguaje devocional.

\section{Tras las huellas textuales del Santo DaIme}

En los poemas de Aguas aéreas pueden reconocerse las operaciones de artificialización características del neobarroso, al mismo tiempo que se advierte la integración de un léxico nuevo vinculado a la práctica del Daime. Éste se evidencia con la aparición de referencias desprendidas de frases de índole espiritual y otras ligadas a aspectos prácticos del rito. Su reconocimiento demanda la familiaridad previa del lector con los rasgos llamativos de la espiritualidad, ya que éstos no son explicitados en los textos como elementos constitutivos de ella.

De este modo, reconocemos en la sexta estrofa del poema "Titilar de ebonita", dos versos escritos en cursiva en los que aparecen dos preguntas que parecen corresponder a un momento de lucidez metafísica en el marco de una proliferación neobarroca: “AAdónde se sale cuando no se está? ¿Adónde se está cuando se sale?” (Poemas 257). Estas preguntas pueden ser consideradas como indicadores de la conciencia que el poeta tenía del éxtasis místico como una salida de sí, un errar más allá del cuerpo. Resulta importante precisar que en la mayor parte de los casos las referencias a la doctrina daimística se manifiestan como una enumeración discontinua de elementos estructurantes de su cosmogonía, relativos principalmente a la comunión entre la liana sagrada, otras yerbas animizadas o divinizadas, y la presencia de la Luz y la Fuerza.

- Revista Iberoamericana, Vol. LXXXIV, Núm. 263, Abril-Junio 2018, $375-390$
ISSN 0034-9631 (Impreso) 
En el poema "VII" encontramos una suerte de descripción de los pasos rítmicos que los oficiantes del rito debían realizar al mismo tiempo que cantaban el himno. ${ }^{11}$ En estos versos se presenta una yuxtaposición de dominios léxicos relativos al ritmo, armonía, luz, color, vegetales. De este modo, el vaivén del pie se urde con el coro vinculándose de inmediato con un campo semántico relativo a la luz y el color, constituido básicamente por los siguientes elementos: lámpara, verberación multicolor, estela en remolinos de haces, derretir grisú de pompas irisadas, lianas barnizando torsiones, adivinados al trasluz del lino, rijo en el rutilar de los colores. Como puede observarse se trata de una sucesión de metáforas puras que complejizan una eventual reconstitución de lo referido, pero que, sin embargo, constituyen referencias tangenciales a la figuración luminosa de la divinidad en el Daime.

Es interesante observar como dentro de estos elementos léxicos recién enumerados hay uno disonante: verberación multicolor, en el que advertimos que la recurrencia del tema de la luz estimula la asociación de la primera palabra a la reverberación: "Dicho de la luz: Reflejarse en una superficie bruñida" (RAE); sin embargo, la ausencia de la sílaba re lo convierte en " 1 . tr. Azotar, fustigar, castigar con azotes. U. t. c. prnl. 2. tr. Azotar el viento o el agua en alguna parte." (RAE), generando un inesperado nexo con el elemento predominante del poemario, el agua. Además de la referencia a la danza rítmica y al coro característico, se menciona el uniforme de los fardados, generalmente fabricado con lino blanco: "muslos morenos, adivinados / al trasluz del lino en el vaivén del pie" (265).

De esta forma, los aspectos constitutivos del rito se mezclan con consideraciones metafísicas como la comunión de cuerpo y vegetal -miembros enyedrados, lianas barnizando torsiones de muslos morenos-, además del sincretismo característico manifestado en el encuentro del incienso y el crucifijo, propios de la imaginería católica, y las referencias a la flora en la que se centra la cosmogonía indígena. Al mismo tiempo, se hacen guiños a una estética kitsch que, en el caso de Aguas aéreas, se manifiesta como un inventario de vestimentas o maquillajes brillantes o llamativos, elementos utilizados para causar la impresión de materias preciosas y lujosas en un

11 Transcribimos los primeros quince versos de un total de 23: "EL PIE, EL VAIVEN DEL PIE, el empellón del piso en el empeine, / lisa combinación urdía su trenza, etérea, con el coro, el ímpetu del / coro, el embalse de voces en elevado enjambre circuía las lámparas / de una verberación multicolor, rosada correa la que atando al des- / mayo el temblor de los tucos liberaba la lívida flotación de la este- / la en remolinos de haces, tan livianos, despeinaban el fleco con el / roce de un ánima, de un aura, el rodete corona sacerdotisas blancas, limousine de charol que embarcaba los hálitos, las ansias, al / derretir grisú las pompas irisadas, de rosar la grisura con un golfo / de incienso, un abanico de humo, ola, orla y aureola de la luz, cru- / cifijo estirado hasta el tonseo de miembros enyedrados, escultura / de lianas barnizando torsiones de los muslos morenos, adivinados / al trasluz del lino en el vaivén del pie, sur timo, rijo en el rutilar de / los colores, tenía una fijeza de marea abrazando el pantano costa- / nero $[\ldots] "$ (Poemas 265). 
contexto popular. Se podría decir que la manifestación de este patrón estético en Perlongher tiene lugar a través de una modalidad metonímica, no por el retrato del objeto asociado a una estética kitsch, sino más bien por la enumeración caótica de las fibras o materias que lo componen.

Es importante consignar que los elementos de dicho patrón estético integrados por la textualidad daimística se encuentran con los que el neobarroso ya poseía en esta misma línea, indiferenciándose sin que podamos discriminar si un determinado giro kitsch corresponde a la mantención de los rasgos de estilo perlonghereano o a un elemento del imaginario del Daime. Más adelante en el poema ${ }^{12}$ reconocemos la referencia a la chacrona -la hoja, femenina-, yerba que en la cosmogonía daimística se identifica a lo femenino y que en el poema va vinculándose gradualmente a una estética kitsch, en la medida en que la mención inicial termina matizándose con los atuendos de un espectáculo de revista gracias a la mención del brillo de la estrella, la purpurina en el vestido de noche de la diosa (265).

El kitsch en el Daime se asocia al lenguaje hímnico, a la decoración devota de las iglesias, así como también a las mirações -este concepto suele ser traducido por los estudiosos delárea como miraciones y mareaciones-provocadas por la ayahuasca. Estas corresponderían a lo que Lapassade denomina "états modifiés de conscience (EMC)" los que describe como "un certain nombre d'expériences au cours desquelles le sujet a l'impression que le fonctionnement habituel de sa conscience se dérègle et qu'il vit un autre rapport au monde, à lui-même, à son corps, à son identité" (Les états 48) y que, en el caso del Daime, son producidos por el consumo de la bebida psicoactiva y la estimulación causada por los himnos y su percusión. Estudios al respecto han detectado la aparición de:

[...] entidades que pueden adoptar la forma de animales, shamanes indios o mestizos, negros, empresarios extranjeros, blancos, caucheros, princesas salidas de los cuentos de hadas europeos, ángeles armados de espadas de la iconografía cristiana, oficiales del ejército, médicos célebres o hasta seres extraterrestres provenientes de otros planetas. (McRae, Guiado 41)

La diversidad de los elementos presentes en las visiones que acompañan el éxtasis daimístico dan cuenta de cómo el marco sociocultural del individuo juega un rol

12 "[...] la hoja, femenina, su brujería vegetal, hincaba en los corpúsculos de bruma la hidra, el aullido modulado de la interrogación, en el traspié, en el cimbreo que se arqueaba al resbalar en los listones húmedos, aura mojada por la lama de charcos agrios y en su góndola remontar el aullido, el glanduleo de las velocidades en el légamo, o acaso la isla de neón tullido entre cuyas hendiduras podía vislumbrarse, en los humores de la transpiración, el brillo de la estrella, o eran las purpurinas del vestido de noche de la diosa deseándose brillar" (Poemas 265).

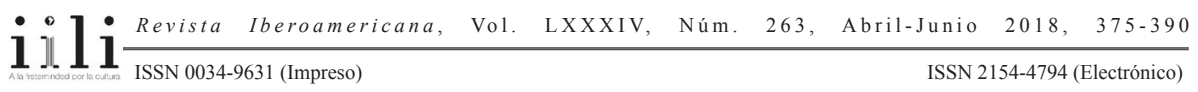


fundamental en la definición del tenor y colorido de sus mirações. ${ }^{13}$ Este aspecto es recogido por Perlongher en sus poemas por medio de una imbricación de elementos relativos al lenguaje devocional de la espiritualidad amazónica. De esto modo, encontramos, por ejemplo, en el poema "El juego del claroscuro" la confrontación de lo que parece ser la referencia a un viaje en canoa, cuyo riesgo determina la posible aparición de animales, y una insólita referencia a una prenda femenina y una revista de moda argentina.

En el fragmento ${ }^{14}$ se puede ver cómo el mundo del Daime se mezcla con elementos reconocibles en el lenguaje poético de sus publicaciones anteriores, en las que la enunciación se vincula constantemente con referentes de la cultura popular. Este no es el único lugar donde los animales típicos de los territorios amazónicos se enfrentan a un léxico que les otorga un matiz kitsch. Sucede también en el caso del poema "Diamante" en donde encontramos:

\author{
Erizos, \\ aguas vivas \\ Caperuzas cartilaginosas \\ Para los maquilleos de las orlas \\ Sirenas de celofán. (Poemas 268)
}

Del mismo modo, en el poema "Paso de la serpiente" en el que la silenciosa y solemne entrada de la serpiente en escena descrita en la primera estrofa se convierte en "SERPENTINA DE COBRAS en el ballet mohave" (Poemas 297). A estos ejemplos de concomitancia entre el mundo referencial del Daime y el decir neobarroso se pueden sumar la trascendencia metafísica de la luz en la espiritualidad amazónica y su avenencia con la inclinación por lo rutilante que describía la poesía anterior de Perlongher.

A estas concomitancias estéticas, se suman otros ejemplos en los que podemos reconocer la afición del poeta por ocultar referencias escatológicas bajo matices de

${ }_{13}$ Pierre Riffard define el trance como "un état modifié de conscience impliquant d'abord un dédoublement, le vécu d'une division ou multiplication de personnalité (corps/âme, esprit propre/esprit étranger...), ensuite un automatisme psychologique, l'impression de subir certains phénomènes psychiques (autonomie de l'âme, incorporation d'un esprit...)" (288), trazando así las etapas de la experiencia extática. De esta secuencia - particularmente de la etapa de automatismo psicológico-se desprende que las percepciones del individuo en trance estén, en gran medida, definidas por su disponibilidad cultural $\mathrm{y}$ religiosa.

14 "Había el peligro de la gran serpiente fluvial, la ame- / naza sombría de la raya, la sonrisa desconfiada de los yacarés y la / raída sombra de una tortuga al sumergirse entre las estelas albo- / rotadas. Todo tan leve y al / mismo tiempo tan caliente, tan ex- / hausto. Nos doblega con su inmensidad el cielo como un tapado / celeste inspirado en Femirama. Una sutil femineidad cincela con/delicadeza los cuerpos trabajados (a tachas) de los que reman y / sus gestos ágiles como panteras en el marihuanal" (Poemas 283).

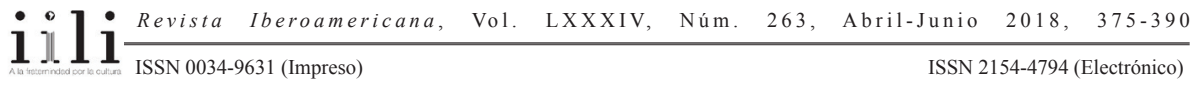


rutilancia. Es así que en el poema "XII"15 se hace referencia al acto de consumir la bebida ritual y a sus consecuencias de índole alucinatoria y también a los efectos secundarios que éste tiene a nivel estomacal. Los elementos que indican el consumo de la ayahuasca estarían principalmente concentrados en las tres primeras estrofas en las que se hace referencia a un "cálice / cáliz" y a beber completamente su contenido hasta que "no dejase ni una gota". En las estrofas sucesivas se intercalan elementos que denotan riqueza como el brocado, que se define como: "Dicho de una tela: Entretejida [sic] con oro o plata" (RAE), el guadamecí en topacio "Cuero adobado y adornado con dibujos de pintura o relieve" (RAE), matizados con referencias al sistema digestivo a través de la palabra borborigmo, movimientos y sonidos intestinales. Luego se incluye la palabra tremor, la que en español refiere al comienzo del temblor y en portugués al "movimento violento e vibratório em diversas direções" (PRIBERAM) lo que hace aumentar la idea de indigestión. A continuación, se menciona la definición de la chata, "Bacín plano, con borde entrante y mango hueco, por donde se vacía. Se usa como orinal de cama para los enfermos que no pueden incorporarse" (RAE) que aparece, posteriormente, en una versión más fastuosa: tibor, "Vaso grande de barro, de China o el Japón, por lo regular en forma de tinaja, aunque los hay de varias hechuras, y decorado exteriormente" (RAE). Hacia el final del poema leemos "por enemas / AGUAS ALUCINADAS / AGUAS AEREAS / aguas visuales / tacto en el colon húmedo" (Poemas 271), versos en los que parece apuntarse la relación de correspondencia entre el título del libro y las heces.

Los últimos versos del poema parecen resumir una asociación antes presentada digresiva y fragmentariamente en el poema que nos enfrenta a una jugarreta típica del neobarroso. Si en Austria-Hungría, primer libro de poesía publicado por Perlongher, pudimos ver asociados por su verso el fasto heroico a las materias excrementicias (Austria-Hungría), en este caso, advertimos que es bajo el espejismo del misticismo que Perlongher esconde su sorpresivo registro escatológico. El agua como elemento natural utilizado en asociación al Daime no podía sino estar definiendo la presencia de lo sagrado, paradójicamente, el poeta lo arrastra, en un par de palabras, nuevamente, al dominio del cuerpo en alusión a la diarrea, efecto secundario de la ingesta de la bebida psicoactiva.

Por otra parte, el Autosacramental do Santo Daime presenta aspectos que lo vuelven un texto bastante peculiar en el concierto de la escritura perlonghereana, sobre todo

15 "INSTARONME / a que empinase el ancho / cálice, no dejase ni una / gota ni una costra / acre. / Nervaduras del cráter craquelé / la visión en el pliegue, la legaña / arañesca, comi- / sura lacar / ahoga en destellos el / dije hundido en el cáliz / cuarteado de pupilas / indecisas / en fuga: / velámenes / brocados, guadamecí / en topacio, incrustación interna, el borborigmo / tremores lacunares / chata en tílburi / en el / tiborcillo / por / enemas / AGUAS / ALUCINADAS / AGUAS AEREAS / aguas visuales / tacto en el colon húmedo / geyser (o / jersey) ístmico. / Que ni un dejo" (Poemas 271).

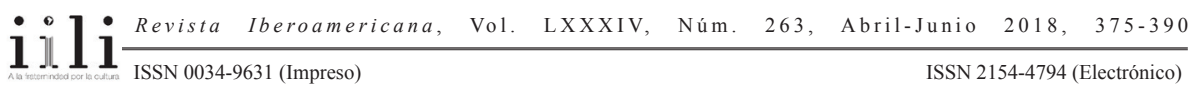


por su género de ostensible finalidad religiosa. Se trata, en efecto, de una composición dramática inconclusa en la que participan alegorías de La Luz, La Ayahuasca, La Fuerza, El Viento, Los Indios, El Coro de Hombres y Mujeres. Sus intervenciones tratan del nacimiento de la ayahuasca a partir de una mixtura de hierbas y de algunos aspectos de la vida en la comunidad del Daime. Su escritura adopta los rasgos de los himnos tales como el verso corto con tendencia octosilábica, la presencia de rimas consonantes y asonantes, así como también un lenguaje que se diferencia del típicamente neobarroso, en la medida en que éste se vuelve más transparente.

El tono no es en ningún caso irónico pudiendo comprobarse su carácter devocional en la inclusión de instrucciones respecto de la disposición que debían tener los feligreses y los signos religiosos, como la cruz de Caravaca, en el rito del Daime. El tono y la transparencia de los enunciados observados en este texto nos permiten pensar que Perlongher no lo habría incluido en alguna de sus publicaciones por no responder a la oscuridad característica del neobarroso. ${ }^{16}$ Este aspecto nos permite colegir que el Autosacramental da cuenta de una motivación ritualística no sólo por su género, sino que también por su tratamiento del lenguaje. De modo general, se reconoce en el poema un tipo de escritura atípico en el neobarroso, salvo pequeñas excepciones en las que es posible reconocer la tesitura perlonghereana como es el fragmento ${ }^{17}$ extraído de una intervención de La Ayahuasca. Las palabras destacadas responden a los criterios preciosistas y enciclopedistas que el poeta utilizara, en ocasiones, para la selección de su léxico.

Otro aspecto interesante del texto y que puede confirmar su inspiración mística es el detallado relato que la voz de La Ayahuasca realiza de su origen constituido por las labores de extracción y preparación de la bebida. Ésta consideraría la síntesis del jagube, hierba masculina, y la chacrona, hierba femenina. ${ }^{18}$ La acuciosidad con la que estos versos caracterizan el proceso otorgan al texto un carácter didáctico que apunta a ilustrar el delicado procedimiento, también ritualizado, del rescate de la hierba en el que, según corroboramos en una carta a Sara Torres de octubre de 1989, Perlongher participó:

16 Recordamos el caso del poema "Tuyú" - publicado en la revista Xul en septiembre del año 1981- no incluido en sus libros de poesía presumiblemente por ostentar un lenguaje en el que las operaciones de artificialización neobarrocas aparecían con mucha menor fuerza.

17 “[...] Puede ser / que algún indio de una tribu / me recogiese de manos / del Dios de la Tempestad, / o que una anaconda iridiscente / mondando con serpear radiante / esmeraldinas caliginosidades, / pariese en el encuentro de las aguas / mi ágil delicuescencia evanescente / y firme; y fuerte; y sobre todo, fuerte" (Papeles 52, énfasis mío).

18 [Habla la ayahuasca]/“Los hombres, entretanto, me buscan/en la selva; o, mejor dicho, buscan/la liana divinal:/ella no es fácil de arrancar, se aferra/con toda (que mucha) su fuerza/al corazón terrestre del alma de las cosas/y sólo permite que la lleven si una música/impregna con delicados tonos de agreste almíbar/la fantasmagoría de la selva" (Papeles 53).

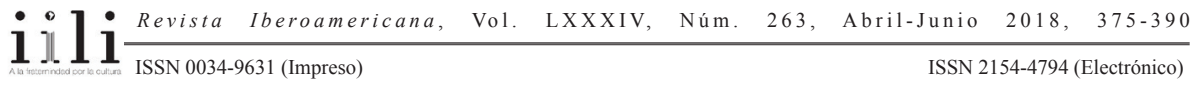


Lo mejor fue participar en el 'feitio', fuimos a desenredar liana de los troncos en el medio de la selva, bajo el ataque de unos mosquitos minúsculos que se meten bajo la ropa. Los hombres se encargan de las lianas y las mujeres de las hojas, al son de cánticos divinos. 'Bater' (macerar) el Daime con una maza sin perder el ritmo de la música (todo rítmico, rimado, musical: 'asociación espírita-musical', defínenla). (Papeles 437)

La confrontación de Aguas aéreas y el Autosacramental do Santo Daime permite contraponer las dos formas en que se sintetizó literariamente el sustrato lexical daimístico. El poeta, consultado por esta dicotomía fue claro en observar que "[s]e puede decir que la poética trabaja en torno del éxtasis pero no necesariamente que lo problematiza" (MacRae, "Recibir" 389). Esta afirmación parece hacerse desde el punto de vista de lo realizado en el interior de su obra en la que su experiencia religiosa es absorbida bajo la forma de una nueva porosidad textual carente de carga doctrinal, con excepción del Autosacramental en el que se aprecia una suerte de pastiche del lenguaje ritual asociable a los feligreses del Daime.

Este recorrido a través de los textos ligados al Daime ha tenido por objeto establecer los alcances textuales que su práctica tuvo en la obra de Perlongher y descartar la idea, alimentada por parte de la crítica, de que su producción poética, particularmente la de Aguas aéreas constituiría un espacio discursivo transido por consideraciones religiosas o el producto de una escritura inspirada, en el sentido religioso del término.

\section{BiBLIOGRAFÍA}

Cangi, Adrián. "Una poética bastarda”. Tsé-Tsé 7/8, Revista de poesía (Buenos Aires 2000): 265-273.

Dicionário Priberam da Língua Portuguesa. Web. 8 de noviembre 2012.

Diccionario de la Real Academia Española. Web. 8 de noviembre 2012.

Eliade, Mircea. Le chamanisme et les techniques archä̈ques de l'extase. Paris: Payot, 1983.

Lapassade, Georges. La transe. Paris: PUF, 1990.

Les États modifiés de la conscience. Paris: PUF, 1987.

MacRae, Edward. "Recibir los himnos, pero celebrar el vacío" (Entrevista). Papeles insumisos. Reynaldo Jiménez y Adrián Cangi, eds. Buenos Aires: Santiago Arcos, 2004.

Guiado por la luna. Shamanismo y uso ritual de la ayahuasca en el culto de Santo Daime. Quito: Abya-Yala, 1998.

El Santo Daime y la espiritualidad brasileña. Quito: Abya-Yala, 2000.

Métraux, Alfred. Réligions et magies indiennes d'Amérique du Sud. Paris: Gallimard, 1967.

Perlongher, Néstor. Poemas completos. Buenos Aires: Seix Barral, 1997.

110 \begin{tabular}{lllll} 
Revista Iberoamericana, Vol. LXXXIV, Núm. 263, Abril-Junio & 2018, $375-390$ \\
\hline ISSN 0034-9631 (Impreso) & ISSN 2154-4794 (Electrónico)
\end{tabular} 
“Autosacramental del Santo Daime”. Tsé-Tsé 9/10. Revista de poesía (Buenos Aires 2001).

"La religión de la ayahuasca". Prosa plebeya. Christian Ferrer y Osvaldo Baigorria, eds. Buenos Aires: Colihue, 1997.

“Carta a Sara Torres del 0810 89”. Papeles insumisos. Reynaldo Jiménez y Adrián Cangi, eds. Buenos Aires: Santiago Arcos, 2004.

Riffard, Pierre A. Nouveau dictionnaire de l'ésotérisme. Paris: Payot, 2008.

Sitio oficial de la Iglesia del Santo Daime. Web. 17 de junio 2014.

Sarduy, Severo. "El Barroco y el Neobarroco". Obras completas. Tomo II. Madrid: Colección Archivos, 1999. 1388-92.

Vecchio, Diego. "Las formas del éxtasis" (Entrevista). Papeles insumisos. Reynaldo Jiménez y Adrián Cangi, eds. Buenos Aires: Santiago Arcos, 2004. 